\title{
Farmers' Access to Agricultural Information Sources: Evidences from Rural Pakistan
}

\author{
Muhammad Yaseen ${ }^{1,2}$, Shiwei $\mathrm{Xu}^{1 *}$, Wen Yu${ }^{1}$, Sadia Hassan ${ }^{3}$ \\ ${ }^{1}$ Agricultural Information Institute, Chinese Academy of Agricultural Sciences, Beijing, China \\ ${ }^{2}$ Department of Agricultural Extension \& Rural Development, University College of Agriculture, University of \\ Sargodha, Sargodha, Pakistan \\ ${ }^{3}$ Graduate School of Chinese Academy of Agricultural Sciences, Beijing, China

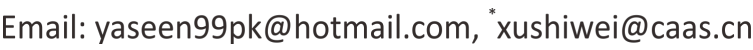

Received 2 February 2016; accepted 23 April 2016; published 30 April 2016

\section{Abstract}

The current study was conducted to probe farmers' accessible agricultural information sources in rural areas of Pakistan. For this purpose a random sample of 160 households from four districts of the Punjab province of Pakistan was selected. Data were collected using validated and expert reviewed questionnaire with the help of interview method. The results revealed that majority of farmers $(47.5 \%)$ ranked neighbor-friends-relatives as first source of information while $31.9 \%$ of farmers ranked this source as second and $33.7 \%$ farmers' ranked it as third major source. With contrast to this very less farmers $(\mathbf{1 0 \%})$ ranked agricultural extension staff as first information source. Keeping in view the study results, the performance of extension staff is not encouraging; therefore government should plan and launch a policy to foster performance of public agricultural extension system to fulfill the advanced technological needs of farmers to flourish sustainable agriculture and rural development.

\section{Keywords}

Extension, Farmer, Information Source, Pakistan

\section{Introduction}

Many efforts have been taken by the government to develop agriculture sector by initiating advanced scientific research approaches to improve production quality and quantity. This sector is strongly associated with others sectors of the economy and plays striking role in improving country's socio-economic development. Agriculture contribution in GDP is almost 21\% giving substantial employment share of 43.5\% [1]. Agricultural information provision is the central element of advanced agriculture system, as well the fundamental and essential promoter for agriculture development, helping for betterment of the rural farmers. As the farmers necessitate a variety of

\footnotetext{
${ }^{*}$ Corresponding author.
}

How to cite this paper: Yaseen, M., Xu, S.W., Yu, W. and Hassan, S. (2016) Farmers' Access to Agricultural Information Sources: Evidences from Rural Pakistan. Journal of Agricultural Chemistry and Environment, 5, 12-19. 
agricultural information, however factors from farmers and information source confined the purpose of agricultural information to boost farmers' livelihood [2]. The key reason restraining farmers to increase agriculture production and income is lack of information sources in rural areas. Improving provision of agricultural information in rural areas might efficiently fill the information gap, certainly facilitating farmers to enhance production and livelihood. As the approaches applied for delivery of agricultural information are limited, so the governments require efficient system to articulate the farmers' needs [3] using diversified information sources to congregate these needs [4]. The major hurdles comprising, inappropriate system of agriculture information management, unworthy information provider, less interest of farmer, and un-consistent farming community development [2]. Transfer of agricultural information to farming community through electronic media was not worth mentioning [5]. However, neighbor-friend-relative farmers and dealers of companies are key information sources of agriculture [6] for rural farmers. Similarly, the print media is the leading and prime source for farmers to get information related to agriculture [4] [7]. Different forms of print media i.e. magazines were ranked as first, newspapers as second, books/booklets as third, and pamphlets as fourth source with reference to their usefulness [8]. Contrary to this the role of extension field staff in dissemination of agricultural information was not significant and their interaction with farmers was meager. Extension field staff should visit farmers on regular basis to encourage and facilitate them for the solution of their problems related to agricultural practices [9].

Overwhelming majority of farmers acquired agricultural information from dealers of different companies and neighbor-friend-relative also appeared as another essential source of information. Likewise, private sector contribute significant role in agriculture information transfer [10]. Role of information and communication technologies in agriculture is imperative, though, large numbers of farmers involve themselves inquiring information, but very small number of farmers utilizes mobile phones for searching such information. Lack of appropriate knowledge is the major cause of this less exploitation of mobile phones for information exploration [11]. Most of rural farmers never visited demonstrations, and never took part in group discussions and lectures [12]. So, the government should legalize private sector to play their role for rapid broadcasting of agricultural information among farmers [13] and they should be provided adult literacy programs to enhance their education level and to make productive use agricultural information sources. Government should also launch mobile vans equipped with video facilities for campaigns to boost up educational awareness of rural farming communities [14].

Agriculture department is investing millions dollar budget allocating almost 8.4 million US dollar for the year 2015-16 to boost up agriculture production by providing extension services and agricultural information through electronic and print media [1] [4] [15]-[17]. Keeping this in view the present study was conducted to investigate farmers' access to agricultural information sources in rural areas of Punjab province of Pakistan. Which, demand fully requires attentions of government to reorganize and reshape existing structure of agricultural extension system to make useful efforts for provision of advisory services and agricultural information sources to rural farming communities. So that marginalized farmers should increase their farm produce and household income to better feed their families and nation toward sustainable agriculture based food safety.

\section{Data and Methodology}

\subsection{Data and Description}

According to results indicated in Table 1, rural farmers ranked top three sources amongst the possible sources list. So, $10 \%$ of farmers ranked agricultural extension staff as top source of information while $3.7 \%$ ranked it

Table 1. Farmers' sources of agricultural information.

\begin{tabular}{ccccccc}
\hline \multirow{2}{*}{ Sources } & \multicolumn{2}{c}{ Ranked 1 $^{\text {st }}$} & \multicolumn{2}{c}{ Ranked 2 $^{\text {nd }}$} & \multicolumn{2}{c}{ Ranked 3 $^{\text {rd }}$} \\
\cline { 2 - 7 } & Frequency & Percentage & Frequency & Percentage & Frequency & Percentage \\
\hline Agri. extension staff & 16 & 10.0 & 6 & 3.7 & 21 & 13.2 \\
Neighbor-friend-relative & 76 & 47.5 & 51 & 31.9 & 54 & 33.7 \\
Company/ dealer & 18 & 11.2 & 67 & 41.9 & 7 & 4.4 \\
Media (print \& electronic) & 11 & 6.9 & 13 & 8.2 & 78 & 48.7 \\
Self-experience & 39 & 24.4 & 23 & 14.3 & 0 & 0 \\
Total & $\mathbf{1 6 0}$ & $\mathbf{1 0 0}$ & $\mathbf{1 6 0}$ & $\mathbf{1 0 0}$ & $\mathbf{1 6 0}$ & $\mathbf{1 0 0}$ \\
\hline
\end{tabular}


second source and $13.2 \%$ farmers ranked it as third source of information. Similarly neighbor-friends-relatives are regarded by $47.5 \%, 31.9 \%$ and $33.7 \%$ of farmers as first, second and third source of information respectively. Company/dealer were observes as first, second and third source of information by $11.2 \%, 41.9 \%$ and $4.4 \%$ of farmers respectively. Likewise, media (print and electronic) was ranked at first position by $6.9 \%$ farmers and second position by 8.2 farmers and third position by $48.7 \%$ farmers as source of agricultural information. In the same way $24.4 \%$ of farmers considered self-experience as main source of agricultural information with first rank and $14.3 \%$ of farmers ranked it at second position.

\subsection{Methodology}

The total sample of 160 farmers has been collected from four districts of Punjab province of Pakistan by simple random techniques, by conducting face-to-face personal interviews of farmers' with the help of authenticated and specialist assessed questionnaire. Initially Punjab, most populated province of Pakistan, was selected purposively being the hub of agricultural crops with compare to other provinces. After that four districts were selected randomly which are Dera Ghazi Khan (D. G. Khan), Muzafargarh, Sargodha and Faisalabad. Then one tehsil from each district was selected randomly comprising; Taunsa, Kot Adu, Sargodha and Faisalabad from D. G. Khan, Muzafargarh, Sargodha and Faisalabad districts respectively. Collected data were fed by using epidata software and analysis was carried out using STATA software and by applying models for results.

For the purpose of data analysis, logistic regression was applied, farmers were chosen from rural community to explore different sources of agricultural information accessible for them or not and this was measured as dichotomy problem. Value 1 is used if agricultural information source is accessible for farmer and 0 otherwise. Specific equation for calculation is given below:

For Government as source of information for farmer:

$$
G s_{i}=F(U i)=f\left(\alpha+\beta X_{i}+\mu\right)=\frac{1}{1+e U_{i}}=\frac{1}{1+e^{-\left(\alpha+\beta X_{i}\right)}}
$$

where $G s_{i}$ is probability of farmer's accessible sources of information from Government, $f$ refers for function of cumulative standard logistic distribution (Wooldridge, 2009), $\beta$ is that parameter which is to be calculated, and $\mathrm{Xi}$ is the variable vector for interpretation. A logistic model can be generated from an underlying variable model (Kostakis, 2014). By assuming that Ui is the un-observed variable to be calculated by:

$$
\log \frac{G s_{i}}{1-G s_{i}}=U i=\alpha+\beta X_{i}+\mu
$$

Suppose that $\mu$ is independent of Xi and is symmetrically distributed to 0 , to generate the probability response for Ui (Wooldridge, 2009) follow given below equations:

$$
U s_{i}=\alpha+\beta_{1} \text { age }+\beta_{2} e d u+\beta_{3} e d u_{-} \text {high }+\beta_{4} \text { off _ farm }+\beta_{5} n_{-} \text {crops }+\beta_{6} n_{-} v l
$$

$G s_{i}$ is binary dependent variables representing the farmers' accessibility towards agricultural information sources as government. While other accessible sources of agricultural information for farmers; private (neighbor-friend-relative), company or dealer, self experience, both (government and company) and media (print and electronic) source have same independent variables like government source (Table 2).

\section{Results and Discussion}

According to results in Table 3 if education level of rural farmers is increased one time then it might increase farmers' access for agriculture information from government department by 1.142 times, similarly if the off-

Table 2. Variables and their explanation

\begin{tabular}{cccc}
\hline Variable & Explanation & Variable & Explanation \\
\hline age & farmmer's age & edu & farmmer's education \\
edu_high & farmmer's house hold highest education & off_farm & Respondent farmer's off-farm job \\
$n \_c r o p s$ & Total number of crops at farmer land & $n_{-} v l$ & Number of villages \\
\hline
\end{tabular}


Table 3. Government as source of information for farmers.

\begin{tabular}{|c|c|c|c|c|c|}
\hline Model & govt_info & Odds Ratio & $\mathbf{Z}$ & $\mathbf{P}>|\mathbf{Z}|$ & \multirow{4}{*}{$\begin{array}{c}\text { Number of obs }=160 \\
\text { LR } \text { chi }^{2}(2)=9.65 \\
\text { Prob }>\text { chi }^{2}=0.0080 \\
\text { Pseudo } \mathrm{R}^{2}=0.0733\end{array}$} \\
\hline \multirow{3}{*}{ Step wise logistic Model } & edu & 1.142494 & 2.49 & 0.013 & \\
\hline & off_farm & 0.3690794 & -1.92 & 0.055 & \\
\hline & _cons & 0.0627201 & -4.46 & 0.000 & \\
\hline \multirow{7}{*}{ Logistic Model } & edu & 1.150426 & 1.58 & 0.114 & \multirow{7}{*}{$\begin{array}{c}\text { Number of obs }=160 \\
\text { LR chi }{ }^{2}(6)=12.30 \\
\text { Prob }>\text { chi }^{2}=0.0556 \\
\text { Pseudo } R^{2}=0.0934\end{array}$} \\
\hline & edu_high & 1.003171 & 0.03 & 0.978 & \\
\hline & age & 1.023019 & 1.12 & 0.262 & \\
\hline & off_farm & 0.3518813 & -1.96 & 0.050 & \\
\hline & n_crops & 1.062647 & 0.14 & 0.887 & \\
\hline & n_lv & 1.002226 & 0.91 & 0.360 & \\
\hline & _cons & 0157327 & -2.66 & 0.008 & \\
\hline
\end{tabular}

farm job for farmers is increased one time it will increase farmers' access for agriculture information from government department 0.062 times. According to results in table if education level of rural farmers is increased one times then it will increase farmers' accessibility of agriculture information from government department by 1.15 times, similarly if higher education is increased by one time it will raise the accessibility of agricultural information from government 1.003 times. While this accessibility increases 1.023 times if the farmers' age is increased one time. If the off-farm job for farmer is increased for one time it will increase accessible government agricultural information sources 0.351 times. Contrarily if the number of crops for rural farmers is increased one time it will increase government department as the accessible source of agricultural information for farming community 1.062 times. Similarly if livestock is increased one time it will also raise accessibility of farmer towards agricultural information 1.002 times.

According to results in Table 4 if education level of rural farmers is increased one time then it will increase farmers' access for agriculture information from private source (neighbor-friend-relative) by 0.743 times. According to results in table if education level of rural farmers is increased one times then it will increase farmers' accessibility of agriculture information from private source (neighbor-friend-relative) by 0.625 times, similarly if higher education is increased by one time it will raise the accessibility of agricultural information from private source 1.296 times. While this accessibility increases 0.984 times if the farmers' age is increased one time. If the off-farm job for farmer is increased for one time it will increase accessible private source agricultural information by 0.879 times. likewise, if the number of crops for rural farmers is increased one time it will increase private source as the accessible source of agricultural information for farming community 0.855 times. Similarly if livestock is increased one time it will also raise accessibility of farmer towards agricultural information from private source by 1.039 times.

According to results in Table 5 if number of crops for rural farmers is increased one time then it will increase farmers' access to agriculture information from company/dealer source by 0.442 times, similarly if the higher education for farmers is increased one time it will increase farmers' access for agriculture information from company/dealer source by 0.773 times. According to results if education level of rural farmers is increased one times then it will increase farmers' accessibility of agriculture information from company/dealer source by 0.982 times, similarly if higher education is increased by one time it will raise the accessibility of agricultural information from company/dealer source 0.787 times. While this accessibility increases 1.016 times if the farmers' age is increased one time. If the off-farm job for farmer is increased for one time it will increase accessible company/dealer source for agricultural information by 0.832 times. likewise, if the number of crops for rural farmers is increased one time it will increase company/dealer source as the accessible source of agricultural information for farming community 0.447 times. Similarly if livestock is increased one time it will also raise accessibility of farmer towards agricultural information from company/dealer source by 1.001 times.

According to results in Table 6 if off-farm jobs for rural farmers is increased one time then it will increase farmers' accessible agriculture information source by himself by 4.92 times, similarly if the higher education for 
Table 4. Neighbor-friend-relative (private) as source of information for farmers.

\begin{tabular}{|c|c|c|c|c|c|}
\hline Model & pvt_info & Odds Ratio & $\mathbf{Z}$ & $\mathbf{P}>|\mathbf{Z}|$ & \multirow{3}{*}{$\begin{array}{c}\text { Number of obs }=160 \\
\text { LR chi }{ }^{2}(1)=16.97 \\
\text { Prob }>\text { chi }^{2}=0.0000 \\
\text { Pseudo } R^{2}=0.1705\end{array}$} \\
\hline \multirow{2}{*}{ Step wise logistic Model } & edu & 0.7434335 & -3.44 & 0.001 & \\
\hline & _cons & 277.2676 & 4.90 & 0.000 & \\
\hline \multirow{7}{*}{ logistic Model } & edu & 0.6251693 & -2.59 & 0.010 & \multirow{7}{*}{$\begin{array}{c}\text { Number of obs }=160 \\
\text { LR chi }^{2}(6)=20.32 \\
\text { Prob }>\text { chi }^{2}=0.0024 \\
\text { Pseudo } R^{2}=0.2041\end{array}$} \\
\hline & edu_high & 1.296666 & 1.29 & 0.196 & \\
\hline & age & 0.9848251 & -0.65 & 0.516 & \\
\hline & off_farm & 0.8790707 & -0.21 & 0.831 & \\
\hline & n_crops & 0.8552307 & -0.31 & 0.756 & \\
\hline & n_lv & 1.03984 & 0.96 & 0.336 & \\
\hline & _cons & 163.2719 & 2.50 & 0.012 & \\
\hline
\end{tabular}

Table 5. Company/dealer as source of information for farmers.

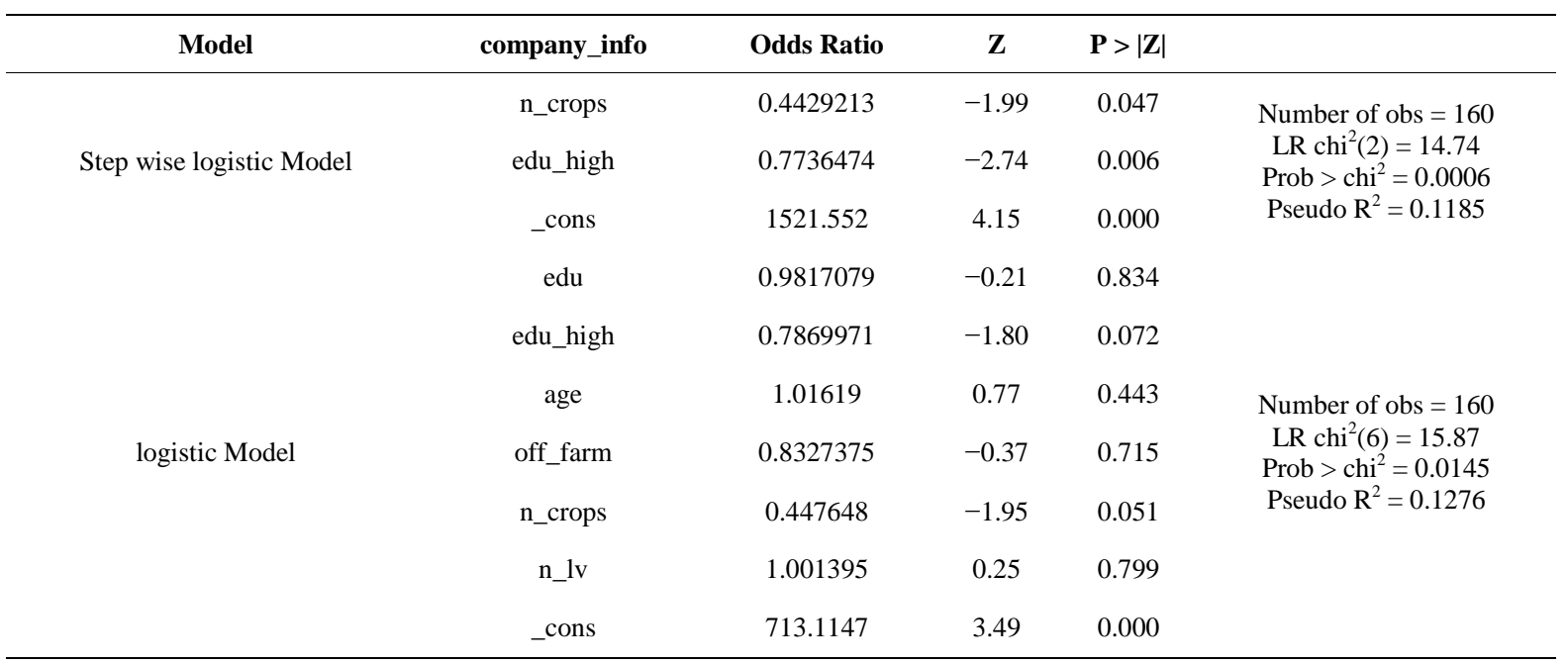

Table 6. Self experience as source of information for farmers.

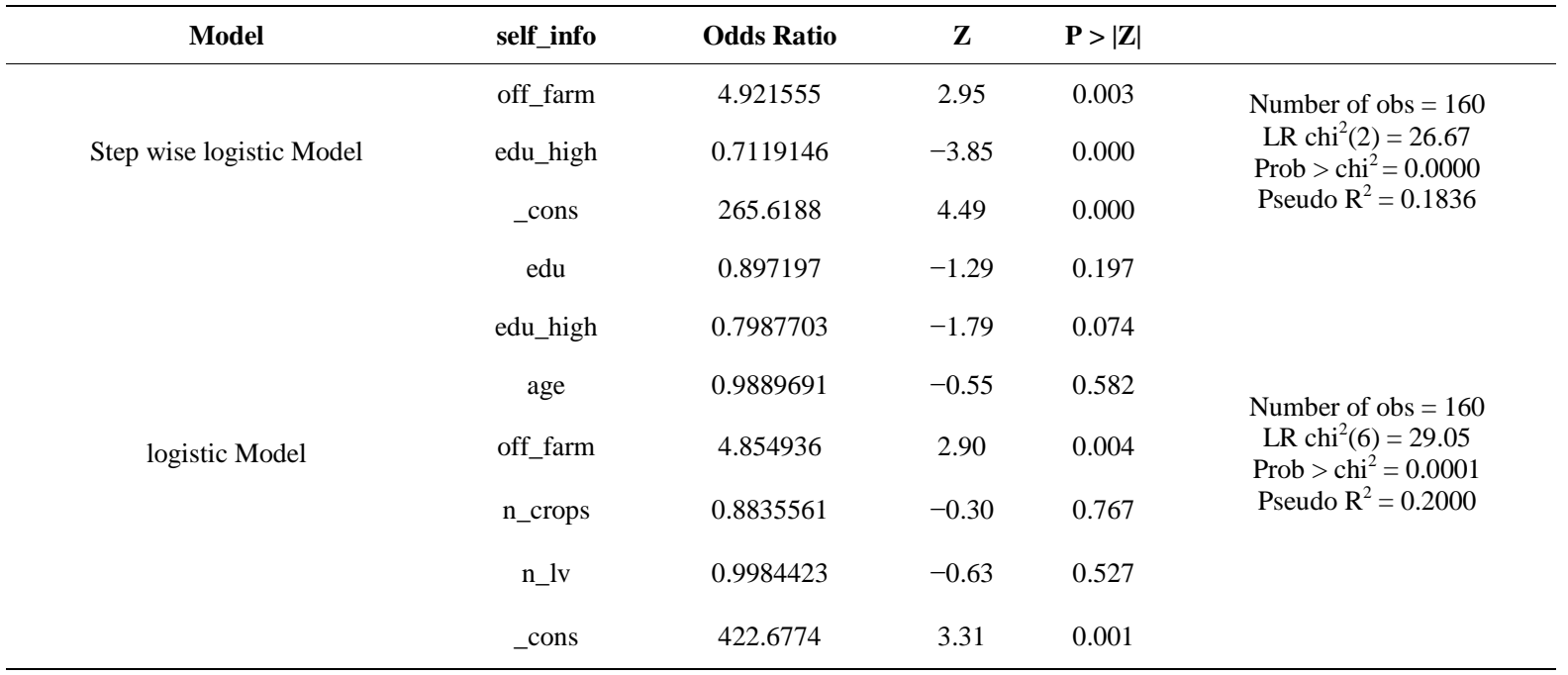


farmers is increased one time it will increase farmers' access for agriculture information from his own experiences by 0.712 times. The results indicate that if education level of rural farmers is increased one times then it will increase farmers' accessibility to agriculture information by self 0.897 times, similarly if higher education is increased by one time it will raise the accessibility to agricultural information by self source 0.798 times. While this accessibility increases 0.988 times if the farmers' age is increased one time. If the off-farm job for farmer is increased for one time it will increase self source for agricultural information by 4.854 times. Likewise, if the number of crops for rural farmers is increased one time it will increase self source as the accessible source of agricultural information for farming community 0.883 times. Similarly if livestock is increased one time it will also raise accessibility of farmer towards agricultural information from self source by 0.998 times.

According to results in Table 7 if number of crops for rural farmers is increased one time then it will increase farmers' accessible agriculture information source from government and company/dealer by 0.386 times, similarly if the higher education for farmers is increased one time it will increase farmers' access for agriculture information from government and company/dealer by 0.635 times. If education level of rural farmers is increased one times then it will increase farmers' accessibility to agriculture information from government and company/dealer by 1.050 times, similarly if higher education is increased by one time it will raise the accessibility to agricultural information from government and company/dealer 0.601 times. While this accessibility increases 1.028 times if the farmers' age is increased one time. If the off-farm job for farmer is increased for one time it will increase government and company/dealer as source for agricultural information by 0.764 times. Likewise, if the number of crops for rural farmers is increased one time it will increase government and company/dealer as the accessible source of agricultural information for farming community 0.371 times. Similarly if livestock is increased one time it will also raise accessibility of farmer towards agricultural information from government and company/dealer by 1.000 times.

According to results in Table 8 if education level for rural farmers is increased one time then it will increase farmers' accessible agriculture information source from media by 1.21 times, similarly if the higher education

Table 7. Govt. \& Company/dealer as source of information for farmers.

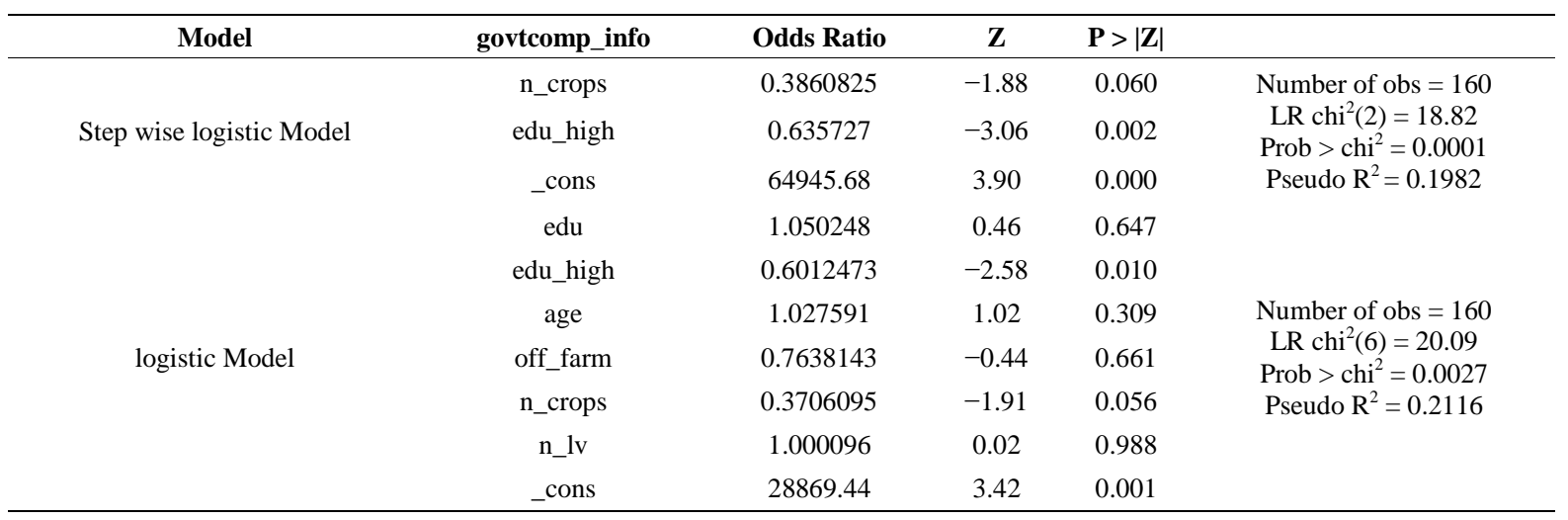

Table 8. Media (print \& electronic) as source of information for farmers.

\begin{tabular}{|c|c|c|c|c|c|}
\hline Model & media_info & Odds Ratio & $\mathbf{Z}$ & $\mathbf{P}>|\mathbf{Z}|$ & \multirow{4}{*}{$\begin{array}{c}\text { Number of obs }=160 \\
\text { LR } \operatorname{chi}^{2}(2)=30.91 \\
\text { Prob }>\text { chi }^{2}=0.0000 \\
\text { Pseudo } \mathrm{R}^{2}=0.2083\end{array}$} \\
\hline \multirow{3}{*}{ Step wise logistic Model } & edu & 1.20837 & 2.12 & 0.034 & \\
\hline & edu_high & 1.233329 & 1.66 & 0.097 & \\
\hline & _cons & 0.0015702 & -4.43 & 0.000 & \\
\hline \multirow{7}{*}{ logistic Model } & edu & 1.211637 & 1.99 & 0.046 & \multirow{7}{*}{$\begin{array}{c}\text { Number of obs }=160 \\
\text { LR } \operatorname{chi}^{2}(6)=33.14 \\
\text { Prob }>\text { chi }^{2}=0.0000 \\
\text { Pseudo } \mathrm{R}^{2}=0.2233\end{array}$} \\
\hline & edu_high & 1.228826 & 1.51 & 0.131 & \\
\hline & age & 1.004333 & 0.22 & 0.824 & \\
\hline & off_farm & 0.8762362 & -0.28 & 0.781 & \\
\hline & n_crops & 1.600446 & 1.18 & 0.238 & \\
\hline & n_lv & 0.9906766 & -0.47 & 0.635 & \\
\hline & _cons & 0.0004732 & -3.81 & 0.000 & \\
\hline
\end{tabular}


for farmers is increased one time it will increase farmers' access for agriculture information from media source by 1.23 times. If education level of rural farmers is increased one times then it will increase farmers' accessibility to agriculture information from media source by 1.21 times, similarly if higher education is increased by one time it will raise the accessibility to agricultural information from media by 1.23 times. While this accessibility increases 1.004 times if the farmers' age is increased one time. If the off-farm job for farmer is increased for one time it will increase media as source for agricultural information by 0.876 times. Likewise, if the number of crops for rural farmers is increased one time it will increase media as the accessible source of agricultural information for farming community 1.60 times. Similarly if livestock is increased one time it will also raise accessibility of farmer towards agricultural information from media by 0.991 times.

\section{Conclusion and Recommendations}

Keeping in view above results the major source of agricultural information for rural communities in Pakistan with regard to agricultural technology is neighbor-friend-relatives with major contribution in top sources of agricultural information. Similarly company/dealers and media (print \& electronic) also contribute equally good share for dissemination of agricultural information. Self experience is also considered as good source of information for farmers. As literacy rate of farmers in rural areas is too much low so there is need to change the manners of farming community towards acceptance of agricultural information related to advanced agricultural technologies from other sources as well as extension field staff. The performance of extension field staff is not encouraging according to findings of this study, therefore government should initially assess the needs of extension field staff to make them fully equipped to transfer agricultural information to farmers well in time for sustainable agriculture. Similarly according to findings the farmers use company/dealer as leading source of information related to new technology soon after its release, while neighbor-friends-relative is second source in this regard contrary to this again extension staff are considered least import instant source of information regarding arrival of new technology. The government should also launch some programs to use diversified agricultural information sources to ensure availability of agricultural information for farmers at village level in form of village information centers. So that farmers can access all possible sources of information according to their need, cropping season, socio-economic and cultural circumstances.

\section{Acknowledgements}

This study was supported by the program CAAS-ASTIP-2016-AII. The authors thanks for support from innovation fund founded by the Chinese Academy of Agricultural Sciences.

\section{References}

[1] Government of the Pakistan (2015) Economics Survey 2014-15, Ministry of Finance and Economic Affairs, Government of Pakistan, Islamabad Pakistan.

[2] Li, Q. and Baoguo, D. (2011) Study on Agricultural Information Service System-Analysis Based on Farmer's Demand of Guangdong. Guangdong Agricultural Sciences, 38, 229-231.

[3] Chen, H.-K. and Wu, Y.-C. (2009) Investigation and Analysis of Farmer's Information Service: Take Yingshan County of Hubei Province as an Example. China Population, Resources and Environment, 19,169-172.

[4] Farooq, S., Muhammad, S., Chauhdary, K.M. and Ashraf, I. (2007) Role of Print Media in the Dissemination of Agricultural Information among Farmers. Pak. J. Agri. Sci., 44, 378-380.

[5] Khan, G.A., Muhammad, S., Chaudhry, K.M. and Khan, M.A. (2010) Present Status and Future Preferences of Electronic Media as Agricultural Information Sources by the Farmers. Pak. J. Agri. Sci., 47, 166-172.

[6] Irfan, M., Muhammad, S., Khan, G.A. and Asif, M. (2006) Role of Mass Media in the Dissemination of Agricultural Technologies among Farmers. International Journal of Agriculture \& Biology, 8, 417-419.

[7] Rehman, F., Muhammad, S., Ashraf, I., Chaudry, K.M., Ruby, T. and Bibi, I. (2013) Effect of Farmers' Socioeconomic Characteristics on Access to Agricultural Information: Empirical Evidence From Pakistan. The Journal of Animal \& Plant Sciences, 23, 324-329.

[8] Rehman, F., Muhammad, S., Ashraf, I. and Hassan, S. (2011) Factors Affecting the Effectiveness of Print Media in the Dissemination of Agricultural Information. Sarhad J. Agric., 27, 119-124.

[9] Ahmad, M., Akram, M., Rauf, R., Khan, I.A. and Pervez, U. (2007) Interaction of Extension Worker with Farmers and Role of Radio and Television as Sources of Information in Technology Transfer: A Case Study of Four Villages of Dis- 
trict Peshawar and Charsadda. Sarhad J. Agric., 23, 515-518.

[10] Yaseen, M., Siddiqui, B.N., Ali, M. and Ameen, M. (2014) Role of Private Sector in Dissemination of Agricultural Information among Cotton Growers in Punjab Pakistan. Universal Journal of Agricultural Research, 2, 89-92.

[11] Tadesse, G. and Bahiigwa, G. (2015) Mobile Phones and Farmers’ Marketing Decisions in Ethiopia. World Development, 68, 296-307. http://dx.doi.org/10.1016/j.worlddev.2014.12.010

[12] Khatam, A., Muhammad, S., Ashraf, I. and Pervez, A.K.M.K. (2013) Effectiveness of Group Contact Methods in Diffusion of Agricultural Technologies among the Farming Community. Journal of Biodiversity and Environmental Sciences, 3, 264-268.

[13] Arfan, M., Ali, S., Khan, F.U. and Khan, G.A. (2013) Comparative Analysis of Punjab Agriculture Helpline and Other Agricultural Information Sources for the Farmers in District Lahore. J. Agric. Res., 51, 473-478.

[14] Butt, T.M., Hassan, M.Z.Y., Sahi, S.T., Mehmood, K., Mashood-ul-Subtain and Hassan, N. (2011) Working Effectiveness of Dissemination Channels as Perceived by Potato Growers. International Journal of Agricultural Management \& Development, 1, 1-6.

[15] Directorate General of Agriculture (2016) Our Budget: Extension \& Adaptive Research, Government of the Punjab, Pakistan. http://ext.agripunjab.gov.pk/budget

[16] Directorate of Agricultural Information (2016) Budget: Directorate of Agricultural Information, Government of the Punjab, Pakistan. http://dai.pitb.gov.pk/budget

[17] Government of the Punjab (2016) Budget: Agriculture Department Government of the Punjab, Pakistan. http://www.agripunjab.gov.pk/budget 